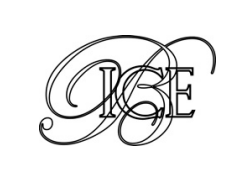

\title{
IRLANDA: CRISIS, PROGRAMA DE ASISTENCIA FINANCIERA Y RESULTADOS
}

Durante la primera década de los años 2000, en Irlanda se gestó una importante burbuja inmobiliaria, acompañada de una fuerte expansión crediticia. Con el pinchazo de la misma, el sector bancario irlandés comenzó a acumular importantes desequilibrios que forzaron la intervención del Gobierno irlandés para garantizar la liquidez y la solvencia de las principales entidades de crédito. Esta intervención puso de manifiesto la existencia de un círculo vicioso entre los sectores público y bancario, que desembocó en la acumulación de un déficit público superior al 32 por 100 del PIB en 2010. Las dudas acerca de la sostenibilidad fiscal y financiera del país forzaron la petición de un programa de asistencia financiera a finales de 2010, que fue concedido por el Mecanismo Europeo de Estabilización Financiera, la Facilidad Europea de Estabilización Financiera, el Fondo Monetario Internacional, Reino Unido, Suecia y Dinamarca. Irlanda consiguió abandonar el programa de asistencia financiera a finales de 2013, tras tres años de aplicación de condicionalidad en los frentes financiero, fiscal y estructural. En la actualidad, Irlanda es el país de la Unión Europea con mayores tasas de crecimiento económico. El propósito de este artículo es analizar en profundidad la crisis, el programa de asistencia financiera y sus efectos en Irlanda.

Palabras clave: Irlanda, programa de asistencia financiera, bail-in, Mecanismo Europeo de Estabilización Financiera, Facilidad Europea de Estabilidad Financiera, Fondo Monetario Internacional.

Clasificación JEL: F33, F34, G21.

\section{Introducción}

Irlanda accedió a la Comunidad Económica Europea (en la actualidad, Unión Europea) en 1973, junto con Reino Unido y Dinamarca, y a la zona euro en 1999. Con un PIB en 2015 de 214.623 millones de euros, Irlanda puede considerarse una economía europea de tamaño mediano.

* Técnico Comercial y Economista del Estado.

Versión de junio de 2016.
Desde su adhesión al euro hasta el año 2008, su PIB experimentó tasas de crecimiento medias anuales superiores al 5 por 100 , cifra que estaba muy por encima de la media de la zona euro, próxima al 2 por 100. Este crecimiento se vio fundamentalmente apoyado en la demanda interna, especialmente en el sector de la construcción. Durante este período de expansión, que finalizó en el año 2008, la tasa de desempleo irlandesa se mantuvo en niveles muy reducidos y cercanos al 4,5 por 100 . 
A lo largo de este tiempo, sus cuentas públicas se mantuvieron muy equilibradas, únicamente se registró un ligero déficit en el año 2002 (-0,4 por 100 del PIB) y en el año 2006, Irlanda logró un superávit del 3 por 100 del PIB. Esto quedó reflejado en la deuda pública sobre PIB, que mantuvo una continua senda decreciente, tocando suelo en el año 2006 con un 24,9 por 100 del PIB.

El sector bancario también presentaba un buen aspecto, ya que la tasa de préstamos morosos sobre préstamos brutos se mantuvo entre el 0,5 y el 1 por 100 durante la mayoría de los años de expansión económica.

En lo que respecta al sector exterior, la balanza por cuenta corriente se mantuvo equilibrada entre 2001 y 2004, pasando a presentar un creciente déficit a partir del año 2005, que acabó por ser del 5,6 por 100 del PIB en 2008. Este empeoramiento en el saldo de la balanza por cuenta corriente fue acompañado de la caída en el superávit de la balanza comercial, que pasó del 29,9 por 100 al 13,2 por 100 del PIB en 2008.

Desafortunadamente, el crecimiento registrado por la economía irlandesa hasta el año 2008 estuvo acompañado de una serie de desequilibrios en los sectores fiscal y financiero, que llevaron a la adopción por el país de medidas extraordinarias en 2008 y 2009. Estas medidas extraordinarias no hicieron sino potenciar el círculo vicioso entre el Gobierno y las entidades de crédito, abocando al Estado irlandés a la petición, en noviembre de 2010 , de un programa de asistencia financiera al Fondo Monetario Internacional (FMI), el Mecanismo Europeo de Estabilización Financiera (MEEF), la Facilidad Europea de Estabilización Financiera (FEEF), Reino Unido, Suecia y Dinamarca.

Este trabajo tiene por objetivo analizar la crisis, el programa de asistencia financiera y los resultados de su aplicación en Irlanda. Para ello, en primer lugar, se estudian los desequilibrios generados en los sectores público y financiero entre los años 2000 y 2008. En segundo lugar, se exponen los efectos del estallido de la crisis en el país, las medidas adoptadas por las autoridades irlandesas como forma de mitigar la crisis y los efectos de dichas medidas. En tercer lugar, se examina el programa de asistencia financiera que le fue concedido por el FMI, el MEEF, la FEEF, Reino Unido, Suecia y Dinamarca, reparando especialmente en su financiación y condicionalidad. Por último, se describe la salida de Irlanda del programa de asistencia financiera y su situación actual, como país con mayores tasas de crecimiento de toda la UE.

\section{Los desequilibrios generados durante la década de crecimiento}

Como se ha mencionado en la introducción, el crecimiento económico registrado por la economía irlandesa hasta el año 2008 (año incluido) se apoyó fundamentalmente en la demanda interna. Este crecimiento se tradujo en un severo aumento de los precios de los activos financieros e inmobiliarios.

En efecto, como puede apreciarse en el Gráfico 1, el ISEQ, principal índice bursátil irlandés, experimentó una fuerte y prolongada subida entre los años 2002 y 2007, que se tradujo en una revalorización del índice superior al 140 por 100.

Los precios de los activos inmobiliarios experimentaron subidas también muy pronunciadas, produciéndose una duplicación de los precios entre los años 2000 y 2007, tal y como se refleja en el Gráfico 2.

Estas considerables subidas en los precios de los activos financieros e inmobiliarios, que llegaron a ser tildadas de burbujas, tuvieron un claro impacto sobre las cuentas públicas y el sistema financiero irlandés.

Por lo que respecta a las cuentas públicas, las autoridades irlandesas aplicaron una política $D$ 

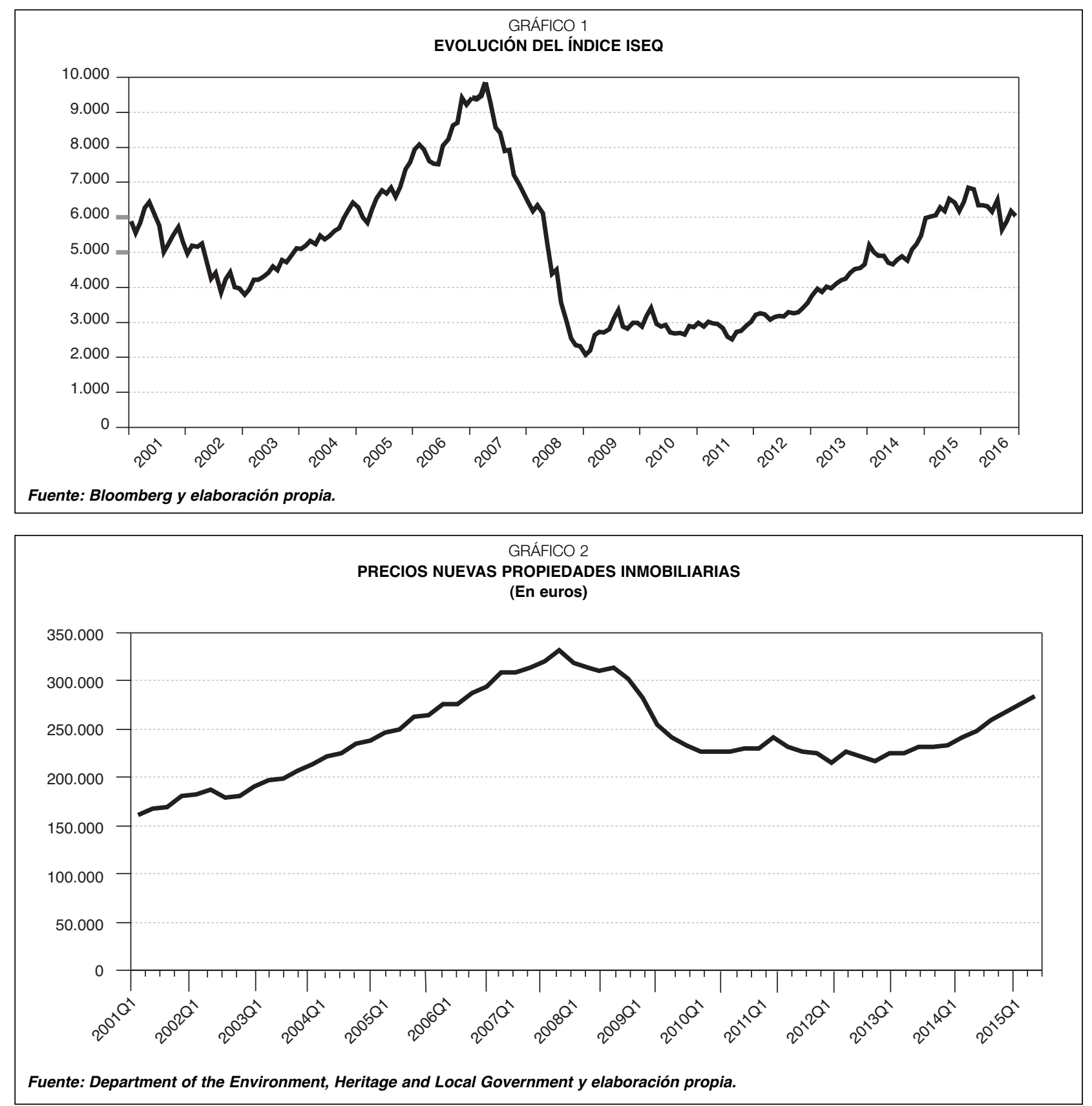

fiscal procíclica fuertemente dependiente de los ingresos públicos procedentes de la construcción. En este sentido, el Gráfico 3 muestra el fuerte incremento experimentado durante los años de expansión económica en la recaudación de los impuestos sobre la propiedad.

En lo que respecta al sector financiero, $y$ tal y como puede observarse en el Gráfico 4, la tasa de préstamos sobre depósitos en Irlanda estuvo muy por encima de la media de la zona euro, especialmente entre los años 2006 y 2010. Esto fue acompañado de unos estándares en la concesión de crédito y una política de supervisión muy laxos.

Así las cosas, durante los primeros años de la primera década de los 2000, buena parte de la economía irlandesa se focalizó en el sector de la construcción, que reportó elevados ingresos públicos que se emplearon de manera procíclica. Esta especialización en el sector de la $\triangleright$ 

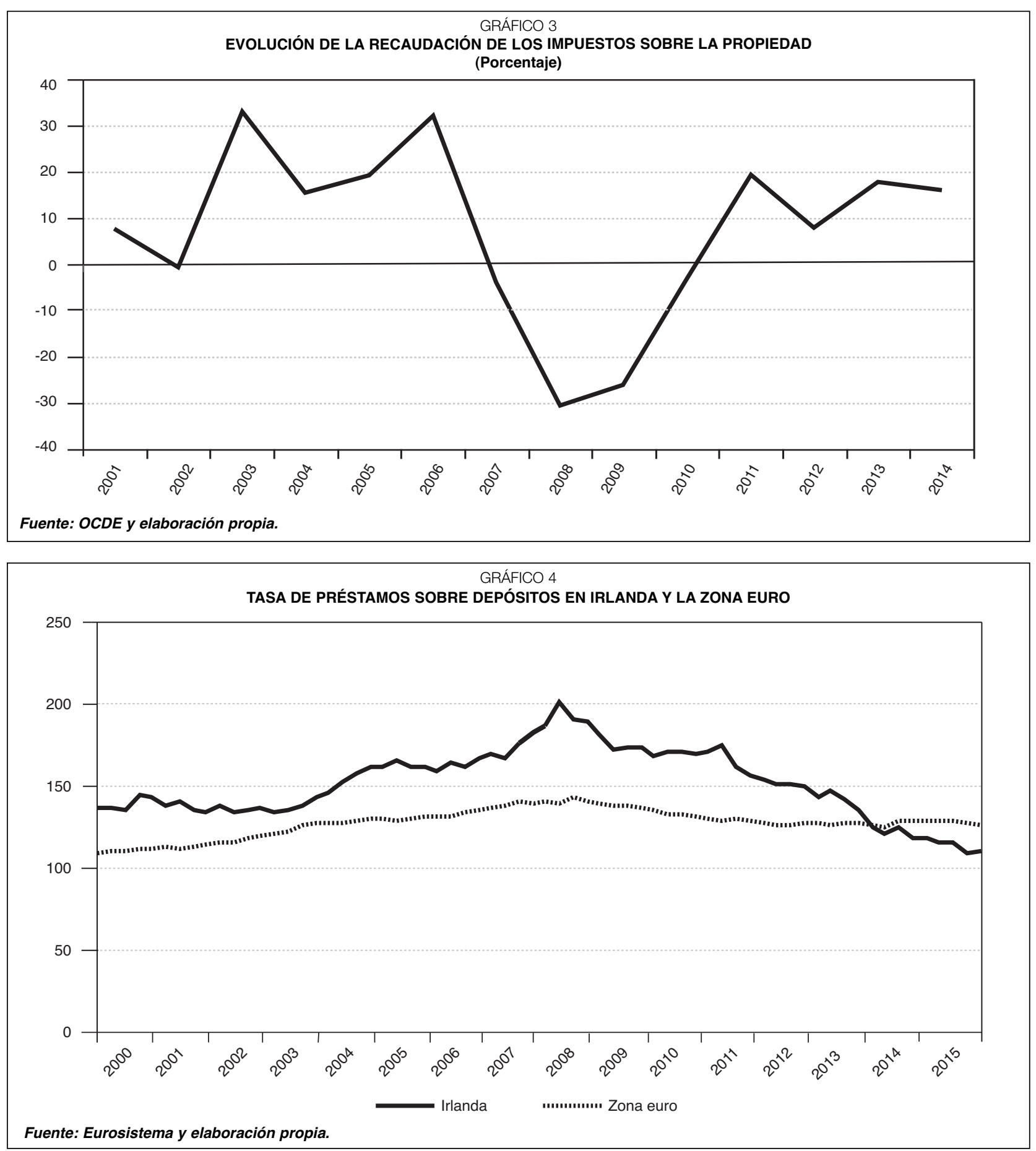

construcción fue además claramente fomentada por el fuerte ciclo expansivo del crédito bancario, que a su vez estaba apoyado en una supervisión muy laxa. Aunque estos factores permitieron elevadas tasas de crecimiento durante unos años, acabaron por generar una fuerte crisis que afectó duramente a la economía irlandesa.

\section{El estallido de la crisis y las medidas adoptadas por las autoridades irlandesas}

El exceso de oferta en el sector de la construcción, las alzas en los tipos de interés y la incertidumbre acerca del tratamiento fiscal de la propiedad llevaron a un frenazo en el sector $D$ 


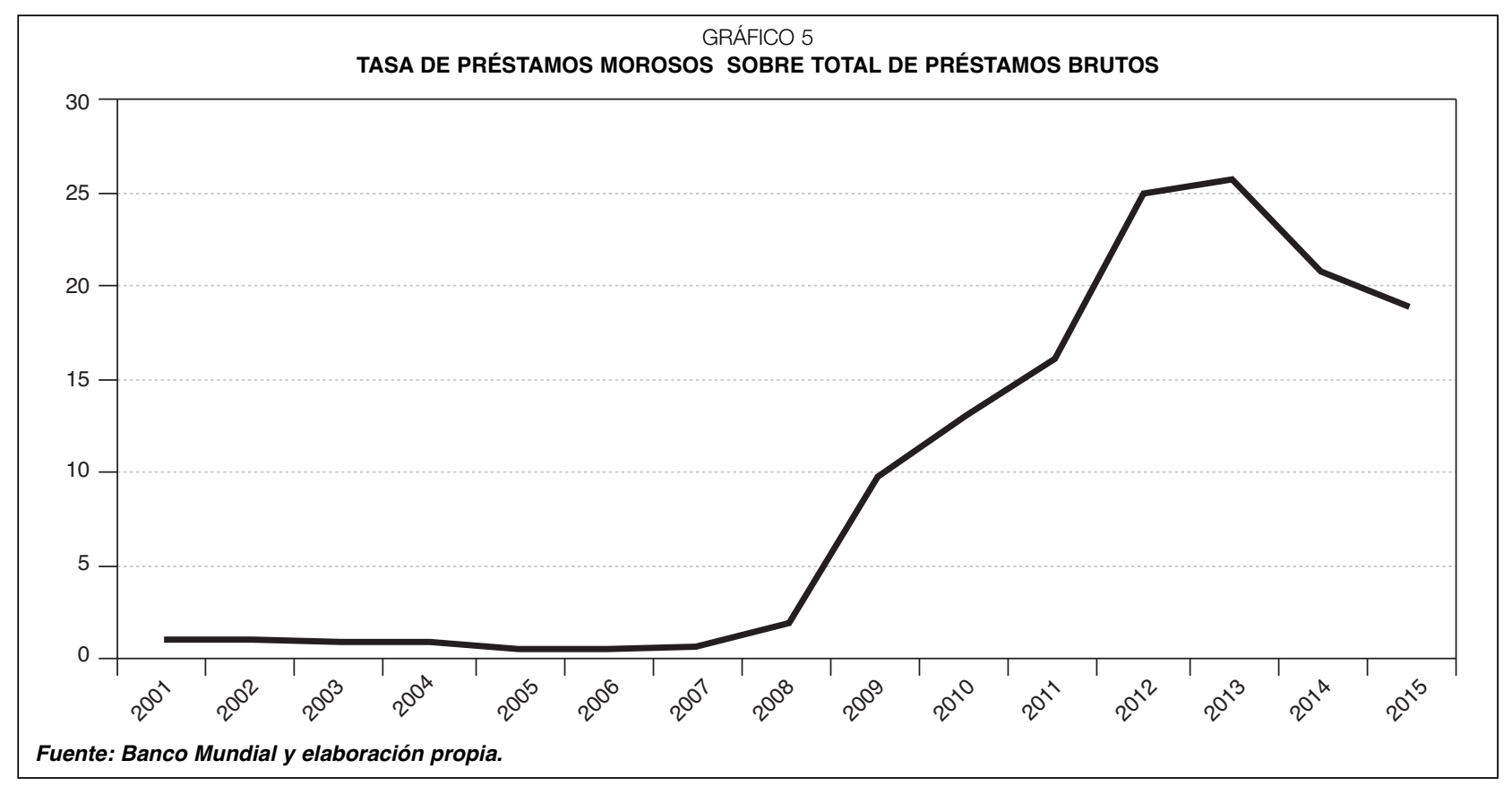

de la construcción, que repercutió negativamente en el conjunto de la economía. Este impacto negativo en la economía real acabó por trasladarse al sector financiero, en el que la tasa de préstamos morosos sobre préstamos brutos creció exponencialmente, llegando a situarse por encima del 25 por 100 según datos del Banco Mundial, tal y como puede apreciarse en el Gráfico 5.

Dado el impacto que las entidades de crédito irlandesas estaban sufriendo por el desplome del sector inmobiliario, las autoridades irlandesas decidieron adoptar una serie de decisiones para mejorar su liquidez y solvencia.

En aras de sustentar la liquidez de la banca irlandesa, el 30 de septiembre de 2008, el Gobierno lanzó el Credit Institutions Financial Support Scheme (CIFS), por el que se ofreció una garantía por un plazo de dos años a un conjunto de pasivos financieros que abarcaban los depósitos minoristas y de empresas, los depósitos interbancarios, la deuda sénior no garantizada, los bonos garantizados y la deuda subordinada con fecha de vencimiento. Las entidades cubiertas por el esquema eran las principales del país, es decir, las consideradas de naturaleza sistémica ${ }^{1}$. Este esquema recibió la conformidad de la Comisión Europea con arreglo a la normativa de Ayudas de Estado el 13 de octubre de $2008^{2}$ y fue aprobado por el Parlamento irlandés el 17 de octubre de 2008. Uno de los elementos clave para la obtención de la conformidad de la Comisión Europea fue la fijación de un precio a la garantía, es decir, las entidades de crédito beneficiarias de la garantía tuvieron que satisfacer una cuota por contar con dicha garantía.

El 9 de diciembre de 2009, el CIFS fue sustituido por el Eligible Liabilities Guarantee Scheme (ELGS). Se decidió que las instituciones y pasivos cubiertos por el CIFS pasarían a estarlo por el ELGS hasta el 29 de septiembre de 2010, fecha de vencimiento del CIFS. Asimismo, las entidades incluidas en el CIFS que también desearan participar en el ELGS debían comunicarlo en un plazo de 60 días desde la entrada en vigor del ELGS. Se permitía también la adhesión de entidades no participantes en el CIFS. El objetivo fundamental $\square$

\footnotetext{
1 Allied Irish Bank, Anglo Irish Bank, Bank of Ireland, EBS Building Society, Irish Life and Permanent, Irish Nationwide Building Society.

2 Decisión de la Comisión de 13 de octubre de 2008 sobre el esquema de garantías para los bancos en Irlanda, caso NN 48/2008, OJ C 312/2008 de 6 de diciembre de 2009.
} 
del ELGS era fomentar el acceso de las entidades participantes a financiación a medio plazo (hasta cinco años), por lo que la garantía se aplicó a nuevos pasivos contraídos por las entidades como depósitos no garantizados, certificados de depósitos no garantizados y deuda sénior no garantizada. Al igual que con el CIFS, para beneficiarse del ELGS, las entidades debían satisfacer una cuota anual que seguiría las Recomendaciones del Consejo de Gobierno del BCE sobre garantías gubernamentales para la deuda bancaria, de 20 de octubre de 2008. Este aspecto resultó clave, nuevamente, para que la Comisión Europea considerara que el ELGS no vulneraba la normativa en materia de Ayudas de Estado $^{3}$ entre el 1 de diciembre de 2009 y el 1 de junio de 2010. Así, las autoridades irlandesas se vieron obligadas a solicitar el visto bueno de la Comisión Europea al ELGS con una periodicidad semestral hasta la expiración definitiva del esquema de garantías el 28 de marzo de 2013.

Por otro lado, como se describirá a continuación, como forma de garantizar la solvencia de las entidades de crédito, el Estado irlandés inyectó fondos públicos en las entidades irlandesas, transfirió ingentes cantidades de recursos públicos a los balances de ciertas entidades a través de las denominadas promissory notes e incluso constituyó una sociedad de gestión de activos.

El 16 de enero de 2009, el Anglo Irish Bank, la tercera entidad de crédito de Irlanda y sin lugar a dudas la más problemática por su elevada exposición al sector inmobiliario, fue nacionalizado. Esta nacionalización fue seguida de la inyección de 7.000 millones de euros de capital público en Allied Irish Bank y Bank of Ireland (3.500 millones de euros en cada entidad). En junio de 2009, el Estado irlandés se vio en la obligación de inyectar 4.000 millones de euros en el Anglo Irish Bank, con el fin de

${ }^{3}$ Decisión de la Comisión de 20 de noviembre de 2009 sobre el esquema de garantías para los bancos en Irlanda, caso NN 349/2009, OJ C 72/2010 de 20 de marzo de 2010. garantizar su solvencia. En marzo de 2010, se inyectaron 100 millones de euros en Irish Nationwide Building Society y EBS Building Society.

También como mecanismo para reforzar la solvencia del sector financiero, el Estado irlandés hizo uso de la figura de las promissory notes, que eran títulos emitidos por el Estado irlandés y que computaban como capital CET14 en los balances bancarios. El Gobierno irlandés inyectó cerca de 31.000 millones de euros en forma de promissory notes en los balances de tres entidades de crédito (25.300 millones de euros en Anglo Irish Bank, 5.300 millones de euros en Irish Nationwide Building Society y 250 millones de euros en Educational Building Society). Estos fondos supusieron un severo incremento del déficit público de Irlanda en 2010, que llegó a alcanzar el 32 por 100 del PIB (si no se hubiera optado por las promissory notes, el déficit público habría sido algo superior al 11 por 100 del PIB). De acuerdo con el perfil de vencimientos de las promissory notes, el Gobierno irlandés debía satisfacer a las entidades de crédito en torno a 3.100 millones de euros al año durante 10 años desde el 2011, lo que incrementaba las necesidades anuales de financiación del Tesoro irlandés en esa cuantía, que equivalía al 2 por 100 del PIB irlandés.

Entre las inyecciones de capital y las promissory notes, el Estado irlandés transfirió más de 46.000 millones de euros al sector bancario en los primeros años de la crisis, con el fin de garantizar su solvencia.

Además de las inyecciones de capital y las promissory notes, en diciembre de 2009, se creó la National Asset Management Company (NAMA) con la finalidad de liberar los balances $\triangle$

\footnotetext{
${ }^{4}$ EI CET1 es un indicador de solvencia que mide la salud financiera de una entidad financiera. La ratio de capital mide, en porcentaje, la relación entre el capital básico (fondos aportados por los accionistas y reservas) y los activos ponderados según riesgo. Una ratio de capital «alta» indica que la entidad cuenta con suficiente capacidad como para hacer frente a eventuales pérdidas en la evolución de su negocio.
} 
de las principales entidades de crédito de Irlanda de los activos más tóxicos y afianzar así su solvencia. El diseño de NAMA no pasaba por que esta sociedad adquiriera los activos tóxicos. En este sentido, se decretó la creación de un Vehículo de Propósito Especial (SPV, por sus siglas en inglés), que estaría participado en un 51 por 100 por inversores privados y en un 49 por 100 por NAMA y que sería el encargado de adquirir los activos tóxicos. Para la adquisición de estos, el SPV emitía deuda, de la cual un 95 por 100 era deuda sénior garantizada por el Estado irlandés y sólo un 5 por 100 era deuda subordinada. La deuda emitida por el SPV pasaba al balance de las entidades de crédito en proporción a los activos que las entidades habían traspasado al SPV. A través de este esquema, NAMA era clasificada como parte del Estado, pero el SPV, al estar participado mayoritariamente por el sector privado, no.

Hasta la fecha, NAMA ha adquirido activos por un valor nominal superior a los $70.000 \mathrm{mi}-$ llones de euros, aplicando un descuento medio del 57 por 100 . El método de valoración de los activos adquiridos fue fijado por la Comisión Europea, que partía como principal indicador del valor económico a largo plazo, es decir, del valor que razonablemente alcanzará un activo en un sistema financiero estable.

A diferencia de la sociedad de gestión de activos española, Sareb, que nació con una duración máxima predeterminada (hasta 2027), NAMA continuará existiendo hasta que el Ministerio de Finanzas irlandés considere que ha cumplido sus funciones y que, por tanto, ya no es necesaria.

A pesar de las medidas adoptadas por el Estado irlandés y de que el propio ministro de Finanzas irlandés en la época, Brian Lenihan, defendió en octubre de 2008 que el rescate a la banca irlandesa había sido el más barato de la historia hasta la fecha, la situación de su sistema financiero seguía siendo crítica. Buena prueba de ello es el recurso de las entidades irlandesas a la financiación del Eurosistema, que en noviembre de 2010 se encontraba en los
140.000 millones de euros (en torno al 85 por 100 del PIB irlandés) 5 .

El severo deterioro del sector financiero irlandés y la intervención del Gobierno para tratar de estabilizar la situación sembraron importantes dudas en los mercados financieros acerca de la solvencia de Irlanda. Estas dudas se tradujeron, como se muestra en el Gráfico 6, en el alza en los tipos pagados por el bono soberano irlandés a 10 años. Ello acabó abocando a Irlanda a la petición de un programa de asistencia financiera.

\section{El programa de asistencia financiera}

\subsection{La solicitud y la concesión del programa de asistencia financiera}

Las autoridades irlandesas solicitaron el programa de asistencia financiera el 21 de noviembre de 2010, presentando el 24 de noviembre de 2010 un Plan Nacional de Recuperación, que cubría los años 2011 a 2014 y servía como base para la negociación de la condicionalidad del programa con las instituciones.

Las instituciones y las autoridades irlandesas llegaron a un Staff Level Agreement el 28 de noviembre de 2010, que fue precisamente el día en que el ECOFIN y el Eurogrupo ${ }^{6}$ acordaron a nivel político la concesión de un programa de asistencia financiera a Irlanda.

Las decisiones formales de concesión del programa de asistencia financiera se tomaron el 7 de diciembre de 2010 por el ECOFIN y el 16 de diciembre de 2010 por la Junta del FMI. De su parte, el Parlamento irlandés aprobó la entrada en el programa el 15 de diciembre de 2010.

\footnotetext{
${ }^{5}$ Carta de Mario Draghi al europarlamentario Matt Carthy, de 17 de febrero de 2015.

6 Eran necesarios los apoyos políticos tanto del ECOFIN como del Eurogrupo, ya que como se explica en el siguiente apartado, parte de la asistencia financiera a Irlanda fue concedida por el MEEF, que cuenta con el apoyo del presupuesto de la UE, y parte por la FEEF, sociedad anónima sita en Luxemburgo que cuenta con las garantías aportadas por los Estados miembros de la zona euro.
} 


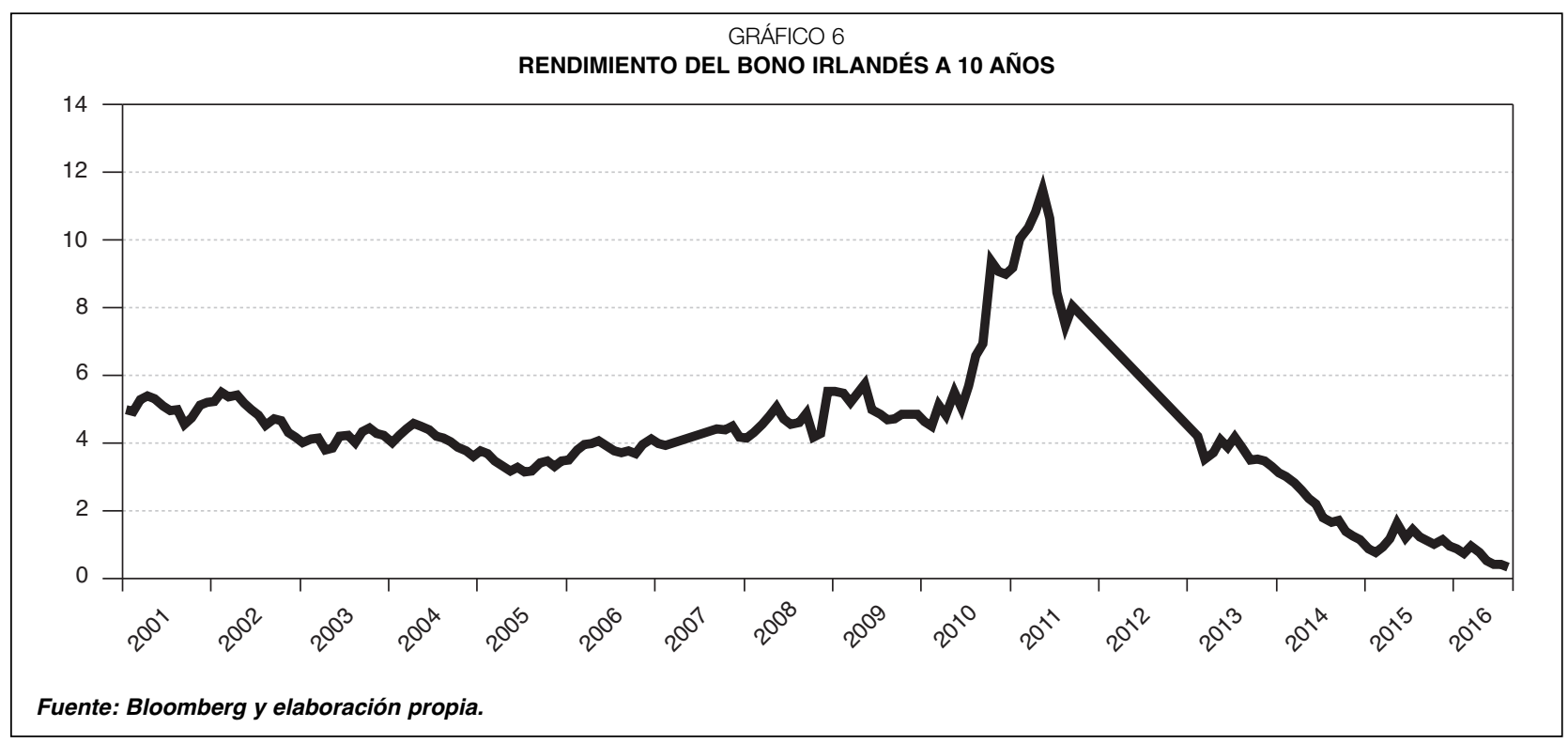

\subsection{La financiación del programa de asistencia financiera, las posteriores reestructuraciones de sus condiciones financieras y los vencimientos anticipados con el FMI}

Las instituciones cifraron el gap de financiación de Irlanda durante la duración del programa de asistencia financiera (hasta diciembre de 2013) en 85.000 millones de euros. De estos 85.000 millones de euros, 50.000 millones correspondían a necesidades de financiación del Gobierno y 35.000 millones de euros a la facilidad de apoyo a la banca, de los que 25.000 millones de euros tenían un carácter contingente.

Los 85.000 millones de euros del programa de asistencia financiera no fueron financiados íntegramente por los acreedores internacionales. Concretamente, 17.500 millones de euros fueron financiados por la propia Irlanda con cargo a su colchón de tesorería y al Fondo Nacional de Reserva de las Pensiones. Los 67.500 millones de euros restantes sí fueron financiados por acreedores internacionales: 22.500 millones de euros por el FMI, 22.500 millones de euros por el MEEF, 17.700 millones de euros por la FEEF y 4.800 millones de euros por préstamos bilaterales (3.800 millones de euros por el Reino Unido, 600 millones de euros por Suecia y 400 millones de euros por Dinamarca).

Inicialmente, los préstamos concedidos por el MEEF y por la FEEF tenían un vencimiento medio máximo de 7,5 años. Sin embargo, con el fin de alisar el perfil de vencimientos del Gobierno irlandés y mejorar sus condiciones de liquidez, el 21 de julio de 2011, la Cumbre de Jefes de Estado y de Gobierno de la zona euro tomó la decisión de ampliar el vencimiento medio máximo del préstamo con el MEEF y con la FEEF hasta los 12,5 y 15 años, respectivamente, y de eliminar el margen de 292,5 puntos básicos que Irlanda debía pagar sobre el coste de financiación del $\mathrm{MEEF}^{7}$, para así alinear esta modalidad de asistencia financiera con la Asistencia Financiera de Balanza de Pagos. Esta decisión de la Cumbre de la zona euro fue finalmente adoptada por el Consejo el 11 de octubre de $2011^{8}$ en lo referente al MEEF y por el Consejo de Directores de la FEEF el 27 de octubre de 2011.

\footnotetext{
${ }^{7}$ Estas mismas decisiones se aplicaron a Portugal. No obstante, hay que hacer notar que el margen que Portugal tenía que pagar inicialmente por el préstamo del MEEF era de 212 puntos básicos y no de 292,5 puntos básicos, como en el caso irlandés.

${ }^{8}$ Decisión de Ejecución del Consejo, de 11 de octubre de 2011, por la que se modifica la Decisión de Ejecución 2011/77/UE relativa a la concesión de ayuda financiera de la Unión a Irlanda (2011/682/UE).
} 
A pesar de las mejoras introducidas en 2011 en las condiciones financieras del programa de asistencia financiera a Irlanda, el Estado miembro debía seguir haciendo frente a importantes picos de vencimientos, especialmente en los años 2019 y 2020. Por ello, con el fin de alisar aún más el perfil de vencimientos de Irlanda, el ECOFIN y el Eurogrupo de 12 de abril de 2013 tomaron la decisión política de incrementar los vencimientos medios máximos de los préstamos contraídos por Irlanda con el MEEF y la FEEF hasta los 19,5 y 22 años, respectivamente ${ }^{9}$. Esta decisión fue efectivamente implementada por el Consejo el 21 de junio de $2013^{10}$ y por el Consejo de Directores de la FEEF el 24 de junio de 2013.

Las mejoras introducidas en las condiciones financieras de los préstamos con el MEEF y la FEEF produjeron un encarecimiento relativo del préstamo concedido por el FMI a Irlanda ${ }^{11}$. Cuando las condiciones financieras del Estado miembro empezaron a mejorar y comenzó a tener acceso a los mercados en condiciones razonables, se planteó la posibilidad de que pagara anticipadamente parte de la asistencia financiera al FMI. Sin embargo, las condiciones financieras de los préstamos concedidos por el MEEF, la FEEF y los acreedores bilaterales (Reino Unido, Suecia y Dinamarca) contenían una cláusula de prepago proporcional de carácter obligatorio ${ }^{12}$, por la que si Irlanda reembolsaba anticipadamente parte del préstamo del FMI, también debía amortizar anticipadamente la parte proporcional de los demás créditos. A solicitud de la propia Irlanda ${ }^{13}$, y con el fin de permitir que el país sustituyera la financiación más costosa del

\footnotetext{
9 Estas decisiones también se aplicaron a Portugal.

10 Decisión de Ejecución del Consejo de 21 de junio de 2013 por la que se modifica la Decisión de Ejecución 2011/77/UE sobre la concesión por la Unión de ayuda financiera a Irlanda (2011/682/UE).

11 Según la política de tipos de interés del FMI, el tipo que debe pagar un país por la asistencia financiera equivale al tipo de interés de los derechos especiales de giro más 100 puntos básicos. Se aplicará un sobrecoste de 200 puntos básicos sobre la parte del préstamo que exceda el 187,5 por 100 de la cuota del país deudor. Este sobrecoste pasará a ser de 300 puntos básicos si el préstamo excede el 187,5 por 100 de la cuota del país deudor durante 51 meses.

12 Cláusula conocida en inglés bajo el nombre mandatory proportionate repayment provision.

${ }_{13}$ Carta enviada por el ministro de Finanzas irlandés, Michael Noonan, a sus homólogos de la UE el 27 de agosto de 2014.
}

FMI por la más barata proporcionada por los propios mercados financieros, los ministros de Finanzas de la UE adoptaron el acuerdo político de inaplicar la citada cláusula de prepago proporcional en el ECOFIN informal celebrado en Milán el 13 de septiembre de 2014. De esta manera, Irlanda anunció su intención de prepagar al FMI en torno a 18.300 millones de euros.

Irlanda llevó a cabo 4 pagos anticipados al FMI por un importe total de 15.691 millones de derechos especiales de giro-DEG- (en torno a 18.000 millones de euros): 5.604 millones de DEG y 2.039 millones de DEG el 10 y el 17 de diciembre respectivamente, 2.826 millones de DEG el 2 de febrero de 2015 y 5.222 millones de DEG el 20 de marzo de 2015. Según el Tesoro irlandés, estas operaciones de preamortización parcial del préstamo con el FMI permitirán generar unos ahorros para el Gobierno irlandés de 1.600 millones de euros. Además, las operaciones de preamortización se financiaron parcialmente con la venta de acciones preferentes del Banco de Irlanda (1.600 millones de euros) y con el repago de instrumentos contingentes de capital de TSB (400 millones de euros).

\subsection{La condicionalidad del programa de asistencia financiera}

Al igual que el resto de programas de ajuste macroeconómico completo, que serían concedidos posteriormente a otros Estados miembros de la zona euro (Portugal, Grecia y Chipre), la condicionalidad del programa de asistencia financiera irlandés giraba en torno a tres pilares fundamentales: condicionalidad financiera, condicionalidad fiscal y condicionalidad estructural. No obstante, como se explicará a continuación, fue la condicionalidad en los sectores financiero y de las cuentas públicas la que constituyó el grueso del programa.

\subsubsection{Condicionalidad en el sector financiero}

Uno de los principales objetivos del programa de asistencia financiera irlandés consistía $\triangle$ 


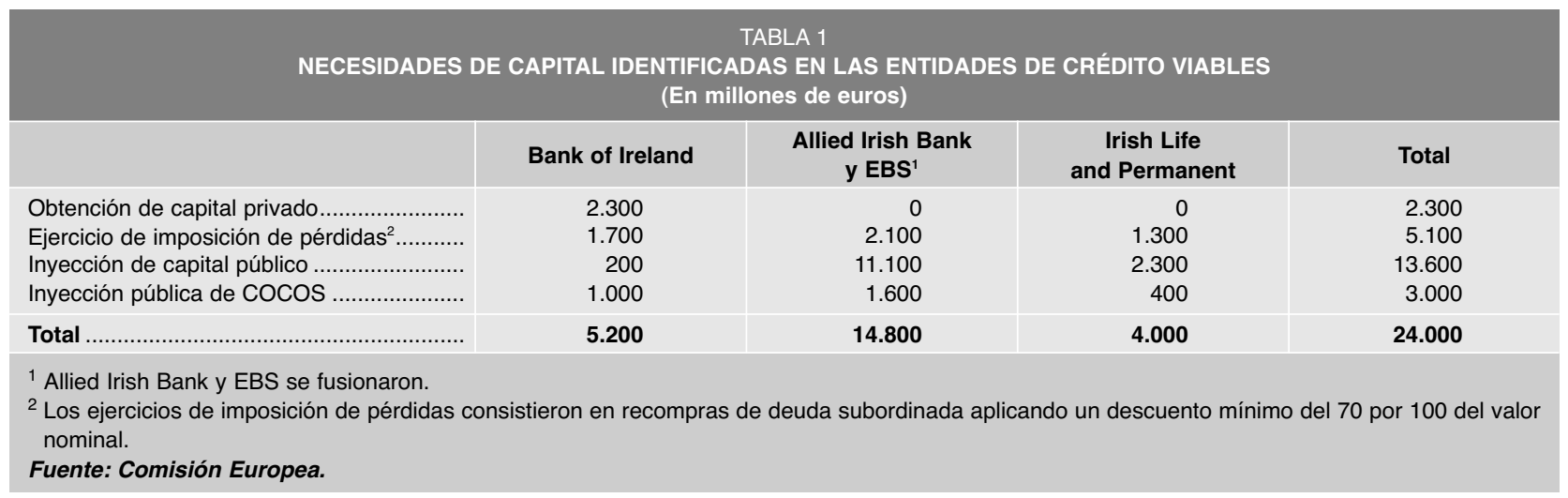

en el saneamiento del sector bancario mediante la recapitalización de las entidades viables (Allied Irish Bank, Bank of Ireland, EBS y Irish Life and Permanent) y la liquidación de las entidades de crédito no viables (Anglo Irish Bank e INBS).

Para medir las necesidades de recapitalización de cada entidad, se realizó un Prudential Capital Assessment Review actualizado ${ }^{14}$, bajo el cual se calcularon las necesidades de capital para un período de tres años, exigiendo un CET 1 mínimo del 10,5 por 100 en el escenario base y del 6 por 100 en el escenario adverso. En total, se identificaron necesidades de capital equiva-

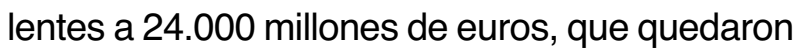
muy por debajo de los 35.000 millones de euros del total del paquete de asistencia financiera que inicialmente se reservaron para la facilidad de apoyo a la banca. Las necesidades de capital identificadas se cubrieron plenamente para julio de 2011, de acuerdo con la distribución indicada en la Tabla 1.

La cobertura de las necesidades de capital de las entidades de crédito consideradas viables garantizó su solvencia y contribuyó a que

\footnotetext{
14 En marzo de 2010, el Banco Central de Irlanda y el Regulador Financiero llevaron a cabo el Prudential Capital Assessment Review, que pretendía determinar las necesidades de capital de las principales entidades del país para el período 2010 a 2012, tanto en un escenario base, en el que se exigía un CET1 del 8 por 100, como en uno estresado, en el que se exigía un CET1 del 4 por 100 . A la luz de los resultados del Prudential Capital Assessment Review, las entidades de crédito irlandesas debían elaborar planes de recapitalización que aseguraran que sus necesidades de capital estarían plenamente cubiertas para finales del año 2010. Como parte del programa de asistencia financiera, se impuso la necesidad de actualizar el Prudential Capital Assessment Review.
}

estas entidades pudieran recuperar el acceso a los mercados financieros. En efecto, para finales del año 2012, Allied Irish Bank y Bank of Ireland consiguieron emitir deuda sénior no garantizada por importe de 500 millones de euros y 1.000 millones de euros, respectivamente.

En cuanto a las entidades no viables, en la segunda mitad de 2011, se procedió con la fusión de Anglo Irish Bank e INBS en un solo grupo: la Irish Bank Resolution Corporation (IBRC). El 8 de febrero de 2013, siguiendo la liquidación de IBRC, el Tesoro irlandés anunció el acuerdo al que se había llegado entre el Gobierno irlandés y el BCE para proceder con el intercambio de las promissory notes del balance de IBRC por ocho series de deuda del Gobierno irlandés. Estas series de deuda eran bonos del Tesoro a tipo de interés flotante, por un importe total de $\mathbf{2 5 . 0 0 0}$ millones de euros, vencimientos de entre 25 y 40 años y con intereses pagaderos cada 6 meses (en junio y diciembre), que vendrían referenciados al euríbor 6 meses más un margen medio del 2,63 por 100.

El programa de asistencia financiera mantuvo intacto el funcionamiento de NAMA. Para el momento de la finalización del programa, NAMA había liquidado ya más del 30 por 100 de los activos (por un valor aproximado de 11.000 millones de euros) y amortizado el 25 por 100 de los bonos sénior emitidos (por un valor aproximado de 7.500 millones de euros). 


\begin{tabular}{|c|c|c|c|c|c|}
\hline \multicolumn{6}{|c|}{$\begin{array}{l}\text { TABLA } 2 \\
\text { SENDA FISCAL OBJETIVO }{ }^{1} \text { EN TÉRMINOS NOMINALES ESTABLECIDA POR LAS INSTITUCIONES } \\
\text { EN EL MEMORANDO DE ENTENDIMIENTO }\end{array}$} \\
\hline & 2011 & 2012 & 2013 & 2014 & 2015 \\
\hline 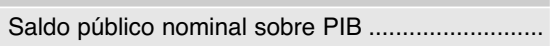 & $-10,6$ & $-8,6$ & $-7,5$ & $-5,1$ & $-2,9$ \\
\hline
\end{tabular}

Con el fin de evitar que la reestructuración del sistema bancario pusiera en peligro la concesión de crédito, se acordó que Allied Irisk Bank y Bank of Ireland concederían al menos 21.000 millones de euros de créditos a pymes a lo largo del programa de asistencia financiera. Este objetivo fue posteriormente complementado con iniciativas como el Microfinance Ireland y el Temporary Loan Guarantee Scheme.

Además de sanear las entidades bancarias irlandesas, el programa exigió un fortalecimiento de la supervisión bancaria. Para ello, en 2011, el Banco Central de Irlanda introdujo un nuevo sistema de supervisión basado en riesgos bajo el cual, el nivel de supervisión sería directamente proporcional a la capacidad de la entidad de poner en peligro la estabilidad financiera. En 2013, se dotó al Banco Central de Irlanda de nuevos poderes y herramientas supervisoras.

Por último, con el fin de fomentar el desapalancamiento de la economía irlandesa, a finales de 2012, se adoptó una reforma del régimen concursal que equilibraba los intereses de acreedores y deudores y fomentaba el recurso a acuerdos extrajudiciales.

\subsubsection{Condicionalidad fiscal}

Las cuentas públicas irlandesas pasaron de registrar un superávit público sobre PIB del 0,2 por 100 en 2007 a un déficit público sobre PIB cercano al 32 por 100 en 2010. Como se ha mencionado anteriormente, una buena parte de este déficit procedió de las medidas de apoyo a la banca prestadas por el Gobierno irlandés. No obstante, aun sin esas medidas de apoyo, el déficit público irlandés hubiera ascendido a más del 11 por 100 del PIB en 2010, lo que denotaba un claro problema en la sostenibilidad de las cuentas públicas relacionado fundamentalmente con el boom inmobiliario vivido por la economía irlandesa. Además, en línea con la evolución del déficit, la deuda pública irlandesa pasó de situarse en el 25 por 100 del PIB en 2007 al 92,2 por 100 del PIB en 2010.

Con el fin de subrayar su compromiso con la consolidación fiscal, las autoridades irlandesas hicieron público un completo plan de reformas fiscales en su Plan Nacional de Recuperación, presentado a los pocos días de la solicitud del programa de asistencia financiera, tal y como se ha mencionado anteriormente. El Plan Nacional de Recuperación recogía una estrategia de consolidación equivalente a 15.000 millones de euros a lo largo de cuatro años. Las medidas de consolidación se repartirían de la siguiente manera: se adoptarían medidas por 6.000 millones de euros en 2011, dejándose para los tres años restantes medidas anuales por 3.000 millones de euros. Dos terceras partes de las medidas contenidas en el Plan Nacional de Recuperación afectaban a reducciones en el gasto público, consistiendo únicamente una tercera parte en incrementos en los ingresos públicos.

Aunque el objetivo de las autoridades irlandesas era reducir el nivel de déficit público sobre PIB por debajo del 3 por 100 para el año 2014, las instituciones adoptaron un enfoque más conservador, concediendo a Irlanda hasta el año 2015 para rebajar su nivel de déficit público sobre PIB por debajo del 3 por $100 \mathrm{y}$ salir así del brazo correctivo del Pacto de $\triangle$ 


\begin{tabular}{|c|c|c|c|}
\hline \multicolumn{4}{|c|}{$\begin{array}{l}\text { TABLA } 3 \\
\text { CUANTÍA Y DISTRIBUCIÓN DE LAS MEDIDAS FISCALES IMPLEMENTADAS POR IRLANDA DURANTE } \\
\text { LA DURACIÓN DEL PROGRAMA } \\
\text { (En millones de euros) }\end{array}$} \\
\hline & 2011 & 2012 & 2013 \\
\hline 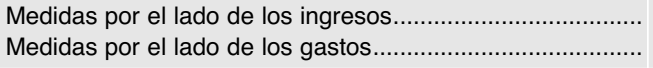 & $\begin{array}{l}2.100 \\
3.900\end{array}$ & $\begin{array}{l}1.600 \\
2.200\end{array}$ & $\begin{array}{l}1.500 \\
1.500\end{array}$ \\
\hline 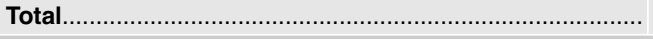 & 6.000 & 3.800 & 3.000 \\
\hline
\end{tabular}

Estabilidad y Crecimiento. De esta manera, las instituciones establecieron como objetivo la siguiente senda fiscal en términos nominales.

Finalmente, durante el programa de asistencia financiera, las autoridades irlandesas implementaron medidas por 6.000 millones de euros en 2011, 3.800 millones de euros en 2012 y 3.000 millones de euros en 2013, repartidas entre ingresos y gastos públicos según figura en la Tabla 3.

En lo que a las medidas adoptadas en el área de ingresos públicos respecta, el objetivo principal pasaba por ensanchar las bases fiscales. Dos terceras partes de las medidas se centraron en los impuestos directos, afectando sólo una tercera parte a los impuestos indirectos. En lo que a los impuestos directos se refiere, la mayor parte de las medidas, centradas en el Impuesto sobre la Renta de las Personas Físicas, se adoptaron en 2011. Con respecto a los impuestos indirectos, destaca la subida del tipo estándar del IVA del 21 al 23 por 100 en 2012.

Por el lado de los gastos públicos, se redujeron los gastos en protección social, que pasaron de suponer el 14,7 por 100 del PIB en 2010 al 13,7 por 100 del PIB en 2013. También se redujeron los gastos en empleo público, tanto a través de la disminución del número de empleados como de los recortes en los salarios públicos, pasando de ser el 11,7 por 100 del PIB en 2010 al 10,7 por 100 del PIB en 2013. Además, gracias a la reducción del consumo intermedio y de la formación bruta de capital fijo, pudo registrarse una consolidación adicional equivalente al 2,4 por 100 del PIB.
Aparte de la adopción de medidas de consolidación fiscal, el programa de asistencia financiera previó también la necesidad de que Irlanda fortaleciera su marco de gobernanza fiscal. Dado que el programa irlandés coincidió temporalmente con la reforma en materia de gobernanza fiscal y económica en el seno de la UE, la condicionalidad en este frente se dirigió a garantizar que Irlanda implementaba todas las reformas europeas ${ }^{15}$. Fruto de estos compromisos, Irlanda adoptó en 2012 el Fiscal Responsibility Act (que fue luego reformado en 2013) y creó el Independent Fiscal Advisory Council, al que se atribuyeron las funciones de controlar el cumplimiento de Irlanda con las reglas fiscales y de reforzar el cuadro macroeconómico empleado como base en la elaboración presupuestaria.

Como consecuencia de todas estas medidas, Irlanda consiguió fortalecer su marco fiscal institucional y reconducir la situación de sus cuentas públicas. En este sentido, habría que destacar que Irlanda consiguió rebajar su déficit público por debajo del 3 por 100 del PIB en 2015 (en línea con los objetivos del programa y no de las autoridades irlandesas, que pretendían pasar al brazo preventivo del Pacto de Estabilidad y Crecimiento al finalizar el año 2014).

\footnotetext{
15 Estas reformas comprenden fundamentalmente la Directiva 2011/85/UE del Consejo, de 8 de noviembre de 2011, sobre los requisitos aplicables a los marcos presupuestarios de los Estados miembros y el Reglamento 473/2013 del Parlamento Europeo y del Consejo de 21 de mayo de 2013 sobre disposiciones comunes para el seguimiento y la evaluación de los proyectos de planes presupuestarios y para la corrección del déficit excesivo de los Estados miembros de la zona euro.
} 


\subsubsection{Condicionalidad estructural}

Irlanda ha sido tradicionalmente una de las economías más competitivas de la UE, con elevados grados de productividad y una población bien formada. Por ello, la condicionalidad estructural impuesta como consecuencia del programa de asistencia financiera no fue especialmente estricta.

En el ámbito del mercado de trabajo, el salario mínimo interprofesional (SMI) por hora se redujo de 8,65 euros (el segundo mayor SMI de toda la UE) a 7,65 euros. Se redujeron el ámbito subjetivo y el importe de los subsidios por desempleo. Desde el punto de vista de las políticas activas de empleo, se integraron las dos agencias irlandesas de empleo, dando lugar al one stop shop Intreo service, que inició su andadura en octubre de 2012. No se adoptaron medidas en materia de protección del empleo, ya que se consideró que la economía irlandesa era lo suficientemente flexible en este sentido.

En cuanto al sector sanitario, la versión inicial del Memorando de Entendimiento no contenía ninguna medida. No obstante, conforme fue transcurriendo el programa y se fue revisando el Memorando de Entendimiento, las instituciones introdujeron condicionalidad en este ámbito. Así, las autoridades irlandesas adoptaron medidas para fomentar el uso de medicamentos genéricos y llegaron a un acuerdo de fijación de precios de medicamentos con la industria farmacéutica para el período 2012 a 2015.

En lo referente al sector energético, las instituciones insistieron inicialmente en la necesidad de que Irlanda procediera con la venta de activos públicos. Sin embargo, las ventas se retrasaron a petición de las propias autoridades irlandesas, que querían esperar al momento idóneo que permitiera maximizar los ingresos por la venta. Este argumento fue aceptado por las instituciones, que consideraron que los ingresos obtenidos por la privatización en el sector energético no eran críticos para el cumplimiento de Irlanda con la senda fiscal.
En Irlanda, los servicios de agua eran proporcionados de manera gratuita en el punto de uso. Ello sumado a la fragmentada red de agua irlandesa, que sufría de una clara falta de inversiones, llevaron a las instituciones a introducir condicionalidad relacionada con este sector en el Memorando de Entendimiento. Así, se transfirió la responsabilidad del suministro de agua a la empresa nacional Irish Water. No obstante, la eliminación de la gratuidad en la prestación de los servicios de agua resultó políticamente compleja, por lo que no pudo adoptarse durante el programa de asistencia financiera.

Por último, el programa permitió un reforzamiento de las políticas de competencia, fomentando la fusión de la Competition Authority y la National Consumer Agency en una única institución, que inició su andadura en noviembre de 2014 bajo el nombre de Competition and Consumer Protection Competition.

\subsection{Desembolsos realizados bajo el programa de asistencia financiera}

El MEEF desembolsó 22.500 millones de euros a Irlanda en 10 desembolsos diferentes, cuya cuantía y vencimientos iniciales aparecen recogidos en la Tabla 4. Es necesario hacer notar que, a diferencia de las extensiones de los vencimientos del préstamo con FEEF, que son automáticas, Irlanda ha de solicitar unos meses antes de cada vencimiento del MEEF la extensión del plazo a la Comisión Europea.

Por su parte, la FEEF realizó 12 desembolsos por un total de 17.700 millones de euros, que aparecen detallados en la Tabla 5.

EI FMI también realizó 12 desembolsos por un total de 19.540 millones de derechos especiales de giro, que aparecen detallados en la Tabla 6.

Finalmente, Irlanda también recibió préstamos bilaterales de Reino Unido (3.200 millones de libras esterlinas en ocho desembolsos), Suecia (600 millones de euros en cuatro $D$ 


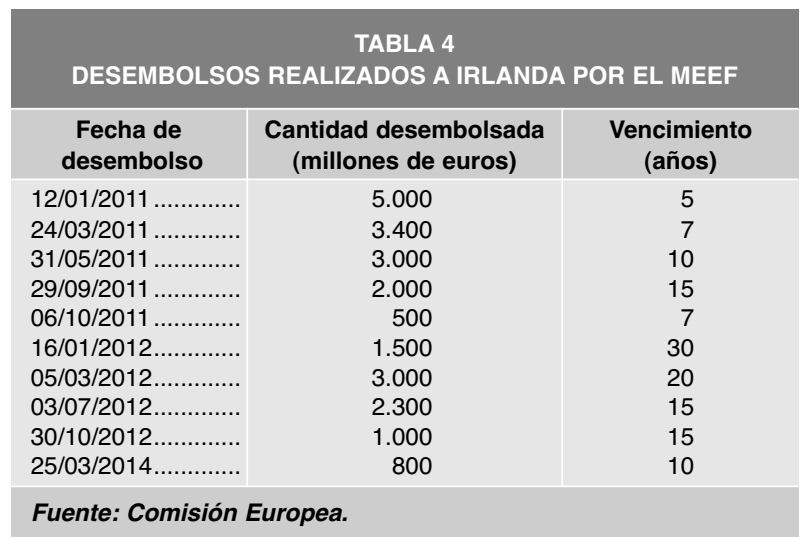

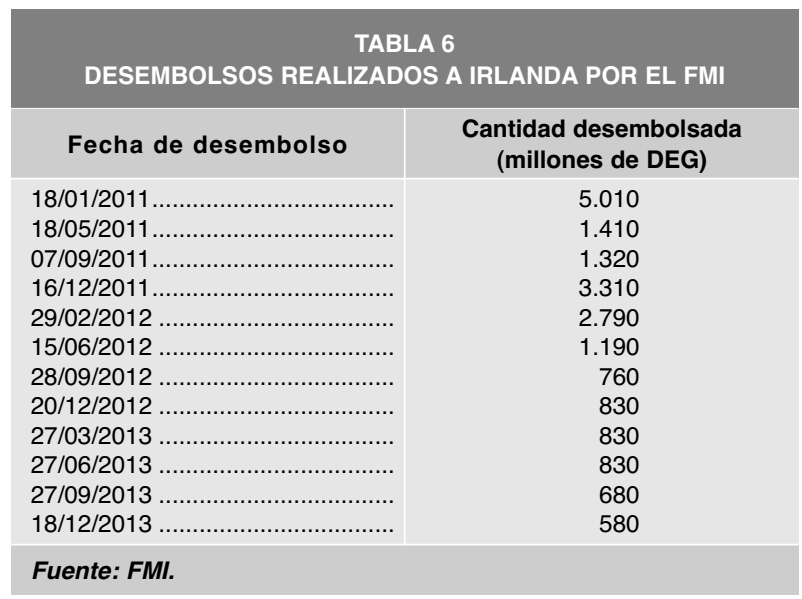

desembolsos) y Dinamarca (400 millones de euros en 4 desembolsos), tal y como se detalla en las Tablas 7, 8 y 9 .

\section{Conclusiones}

El 14 de noviembre de 2013, el Eurogrupo concluyó que el programa de asistencia financiera irlandés había sido un éxito, indicando que el país podría abandonarlo al finalizar el año, como de hecho ocurrió.

En sintonía con el mensaje lanzado por el Eurogrupo, Irlanda ha conseguido dejar atrás la crisis, reconduciendo con firmeza los problemas detectados en las cuentas públicas y en su sector bancario. Irlanda es, sin lugar a dudas, una experiencia de éxito en la aplicación de programas de asistencia financiera.

\begin{tabular}{|c|c|c|}
\hline \multicolumn{3}{c}{ TABLA 5} \\
DESEMBOLSOS REALIZADOS A IRLANDA POR LA FEEF \\
\hline $\begin{array}{c}\text { Fecha de } \\
\text { desembolso }\end{array}$ & $\begin{array}{c}\text { Cantidad desembolsada } \\
\text { (millones de euros) }\end{array}$ & $\begin{array}{c}\text { Vencimiento final } \\
\text { revisado }\end{array}$ \\
\hline $01 / 02 / 2011 \ldots \ldots \ldots .$. & 1.900 & $01 / 08 / 2032$ \\
$01 / 02 / 2011 \ldots \ldots \ldots .$. & 1.700 & $01 / 08 / 2033$ \\
$10 / 11 / 2011 \ldots \ldots \ldots .$. & 900 & $01 / 08 / 2030$ \\
$10 / 11 / 2011 \ldots \ldots \ldots .$. & 2.100 & $25 / 07 / 2031$ \\
$15 / 12 / 2011 \ldots \ldots \ldots .$. & 1.000 & $01 / 08 / 2030$ \\
$12 / 01 / 2012 \ldots \ldots \ldots .$. & 1.200 & $01 / 08 / 2029$ \\
$19 / 01 / 2012 \ldots \ldots \ldots \ldots$. & 500 & $01 / 07 / 2034$ \\
$03 / 04 / 2012 \ldots \ldots \ldots \ldots$. & 2.700 & $01 / 08 / 2031$ \\
$02 / 05 / 2013 \ldots \ldots \ldots .$. & 800 & $01 / 08 / 2029$ \\
$18 / 06 / 2013 \ldots \ldots \ldots .$. & 1.600 & $18 / 06 / 2042$ \\
$27 / 09 / 2013 \ldots \ldots \ldots .$. & 1.000 & $27 / 09 / 2034$ \\
$04 / 12 / 2013 \ldots \ldots \ldots .$. & 2.300 & $04 / 12 / 2033$ \\
\hline Fuente: FEEF. & & \\
\hline
\end{tabular}

En 2014 y 2015, el PIB real irlandés creció un 5,2 y un $26^{16}$ por 100 respectivamente, encabezando el crecimiento económico de la UE. El desempleo ha iniciado una clara senda decreciente, situándose en el 9,4 por 100 a finales de 2015. Las cuentas públicas están cada vez más saneadas: Irlanda consiguió abandonar el brazo correctivo del Pacto de Estabilidad y Crecimiento a finales del 2015, al presentar un déficit público nominal sobre PIB del 2,3 por 100. La deuda pública cerró el 2015 en el 93,8 por 100 del PIB, muy por debajo del 120 por 100 que se registró en 2013.

El tamaño del sector bancario irlandés se ha reducido en más del 30 por 100 y su dependencia con respecto a la financiación del BCE ha caído notablemente. La ratio de préstamos sobre depósitos se ha reducido por debajo del 122,5 por 100 , en línea con el objetivo inicial del programa. Allied Irish Bank y Bank of Ireland volvieron a registrar beneficios en el 2014. La estructura supervisora del sistema bancario irlandés es ahora más resistente.

Hasta la fecha, NAMA ha conseguido amortizar 24.600 millones de euros de bonos sénior, lo que equivale al 81 por 100 de la deuda sénior. Las autoridades irlandesas esperan que, para $\triangleright$

\footnotetext{
16 La cifra de crecimiento del PIB relativa a 2015 ha generado importante polémica. Aunque inicialmente se esperaba que el PIB irlandés en 2015 creciera en torno al 7,8 por 100, la revisión posterior de las cifras puso de manifiesto que esta cifra era del 26 por 100 . Ello ha generado dudas acerca de la metodología estadística empleada para el cálculo del PIB.
} 


\begin{tabular}{|c|c|c|}
\hline \multicolumn{3}{|c|}{$\begin{array}{c}\text { TABLA } 7 \\
\text { DESEMBOLSOS REALIZADOS A IRLANDA POR REINO UNIDO }\end{array}$} \\
\hline Fecha de desembolso & $\begin{array}{c}\text { Cantidad desembolsada } \\
\text { (millones de libras } \\
\text { esterlinas) }\end{array}$ & $\begin{array}{l}\text { Vencimiento } \\
\text { (años) }\end{array}$ \\
\hline 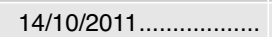 & 400 & 7,5 \\
\hline 30/01/2012 …............. & 400 & 7,5 \\
\hline 28/03/2012 …............. & 400 & 7,5 \\
\hline $01 / 08 / 2012 \ldots \ldots \ldots \ldots \ldots$ & 400 & 7,5 \\
\hline $19 / 10 / 2012 \ldots \ldots \ldots \ldots \ldots$ & 400 & 7,5 \\
\hline $06 / 03 / 2013 \ldots \ldots \ldots \ldots \ldots . .$. & 400 & 7,5 \\
\hline 06/06/2013 …… & 400 & 7,5 \\
\hline 26/09/2013 …............. & 400 & 7,5 \\
\hline
\end{tabular}

TABLA 8

DESEMBOLSOS REALIZADOS A IRLANDA POR SUECIA

\begin{tabular}{|c|c|c|}
\hline Fecha de desembolso & $\begin{array}{l}\text { Cantidad desembolsada } \\
\text { (millones de euros) }\end{array}$ & $\begin{array}{l}\text { Vencimiento } \\
\text { (años) }\end{array}$ \\
\hline $15 / 06 / 2012 \ldots \ldots \ldots \ldots \ldots \ldots$ & 150 & $\begin{array}{l}7,5 \\
7,5\end{array}$ \\
\hline 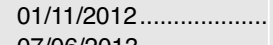 & 150 & $\begin{array}{l}7,5 \\
7,5\end{array}$ \\
\hline 07/06/2013................. & 150 & $\begin{array}{r}7,5 \\
7,5\end{array}$ \\
\hline 07/11/2013 ................. & 150 & 7,5 \\
\hline
\end{tabular}

2018, toda la deuda sénior emitida por NAMA esté ya amortizada.

Si bien la aplicación de programa de asistencia financiera irlandés ha sido una experiencia de éxito, es necesario no pasar por alto una de sus principales lecciones: existe un círculo vicioso entre el Gobierno y las entidades de crédito que puede acabar por arrastrar a toda una economía e incluso, a toda una unión monetaria. Esta lección constituye, sin lugar a dudas, uno de los principales argumentos para continuar con el progreso del proyecto de la unión bancaria. De nada sirve que los Estados miembros de la zona euro adopten planes de reformas a nivel nacional si no se sigue profundizando en conseguir una Unión Económica y Monetaria óptima.

\section{Bibliografía}

[1] BANCO MUNDIAL (2016). Base de datos de tasas de morosidad.

[2] BLOOMBERG (2016). Rendimientos del bono genérico irlandés a 10 años y evolución del ISEQ.

[3] COMISIÓN EUROPEA (2008). Decisión de la Comisión de 13 de octubre de 2008 sobre el esquema de garantías para los bancos en Irlanda, caso NN 48/2008, OJ C 312/2008 de 6 de diciembre de 2009.

\begin{tabular}{|c|c|c|}
\hline \multicolumn{3}{|c|}{$\begin{array}{c}\text { TABLA } 9 \\
\text { DESEMBOLSOS REALIZADOS A IRLANDA POR DINAMARCA }\end{array}$} \\
\hline Fecha de desembolso & $\begin{array}{l}\text { Cantidad desembolsada } \\
\text { (millones de euros) }\end{array}$ & $\begin{array}{l}\text { Vencimiento } \\
\text { (años) }\end{array}$ \\
\hline 30/03/2012 . & 100 & 7,5 \\
\hline $01 / 11 / 2012$. & 100 & 7,5 \\
\hline $04 / 06 / 2013$ & 100 & 7,5 \\
\hline $07 / 11 / 2013 \ldots \ldots \ldots \ldots \ldots \ldots$ & 100 & 7,5 \\
\hline
\end{tabular}

[4] COMISIÓN EUROPEA (2009). Decisión de la Comisión de 20 de noviembre de 2009 sobre el esquema de garantías para los bancos en Irlanda, caso NN 349/2009, OJ C 72/2010 de 20 de marzo de 2010.

[5] COMISIÓN EUROPEA (2011). «The Economic Adjustment Programme for Ireland» Occasional Papers, $\mathrm{n}^{\circ} 76$.

[6] COMISIÓN EUROPEA (2011). «The Economic Adjustment Programme for Ireland, Summer 2011 review», Occasional Papers, $n^{\circ} 84$.

[7] COMISIÓN EUROPEA (2011). «The Economic Adjustment Programme for Ireland, Autumn 2011 review», Occasional Papers, $n^{\circ} 88$.

[8] COMISIÓN EUROPEA (2012). «The Economic Adjustment Programme for Ireland, Winter 2011 review», Occasional Papers, $n^{\circ} 93$.

[9] COMISIÓN EUROPEA (2012). «The Economic Adjustment Programme for Ireland, Spring 2012 review», Occasional Papers, $n^{\circ} 96$.

[10] COMISIÓN EUROPEA (2012). «The Economic Adjustment Programme for Ireland, Summer 2012 review», Occasional Papers, $n^{\circ} 115$.

[11] COMISIÓN EUROPEA (2013). «The Economic Adjustment Programme for Ireland, Autumn 2012 review», Occasional Papers, $n^{\circ} 127$.

[12] COMISIÓN EUROPEA (2013). «The Economic Adjustment Programme for Ireland, Winter 2012 review», Occasional Papers, $n^{\circ} 131$.

[13] COMISIÓN EUROPEA (2013). «The Economic Adjustment Programme for Ireland, Spring 2013 review», Occasional Papers, $n^{\circ} 154$.

[14] COMISIÓN EUROPEA (2013). «The Economic Adjustment Programme for Ireland, Summer 2013 review», Occasional Papers, $n^{\circ} 162$.

[15] COMISIÓN EUROPEA (2013). «The Economic Adjustment Programme for Ireland, Autumn 2013 review», Occasional Papers, $n^{\circ} 167$.

[16] COMISIÓN EUROPEA (2015). «Ex Post Evaluation of the Economic Adjustment Programme Ireland, 2010-2013», Institutional Papers, $\mathrm{n}^{\circ} 004$. 
Judith Arnal Martínez

[17] CONSEJO DE LA UNIÓN EUROPEA (2011). Decisión de Ejecución del Consejo de 11 de octubre de 2011 por la que se modifica la Decisión de Ejecución 2011/77/UE relativa a la concesión de ayuda financiera de la Unión a Irlanda (2011/682/UE).

[18] CONSEJO DE LA UNIÓN EUROPEA (2013). Decisión de Ejecución del Consejo de 21 de junio de 2013 por la que se modifica la Decisión de Ejecución 2011/77/UE sobre la concesión por la Unión de ayuda financiera a Irlanda (2011/682/UE).
[19] DEPARTMENT OF THE ENVIRONMENT, HERITAGE AND LOCAL GOVERNMENT (2016). Base de datos de precios de nuevas propiedades inmobiliarias en Irlanda.

[20] EUROSISTEMA (2016). Base de datos de la tasa de préstamos sobre depósitos en Irlanda y la zona euro.

[21] ORGANIZACIÓN PARA LA COOPERACIÓN Y EL DESARROLLO ECONÓMICOS (2016). Base de datos de la recaudación de impuestos sobre la propiedad. 
IRLANDA: CRISIS, PROGRAMA DE ASISTENCIA FINANCIERA Y RESULTADOS

\begin{tabular}{|c|c|c|c|c|c|c|c|c|c|c|c|c|c|c|c|c|}
\hline \multicolumn{17}{|c|}{$\begin{array}{c}\text { ANEXO } 1 \\
\text { CUADRO MACROECONÓMICO DE IRLANDA ENTRE } 2001 \text { Y } 2016^{(1)}\end{array}$} \\
\hline & 2001 & 2002 & 2003 & 2004 & 2005 & 2006 & 2007 & 2008 & 2009 & 2010 & 2011 & 2012 & 2013 & 2014 & 2015 & 2016 \\
\hline 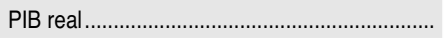 & 5,7 & 6,1 & 4,4 & 4,5 & 6,4 & 5,7 & 6 & $-3,5$ & $-5,5$ & $-0,8$ & 1,4 & 0,2 & 1,4 & 5,2 & 7,8 & 4,5 \\
\hline Consumo privado.... & 5 & 3,4 & 3,4 & 4,1 & 7,2 & 7 & 6 & $-1,8$ & $-5,7$ & 0,5 & $-2,3$ & -1 & 0,1 & 2,1 & 3,3 & 2,5 \\
\hline Consumo público & 10,5 & 7,3 & 3,2 & 1,9 & 3,1 & 5,3 & 6,8 & 2,8 & $-3,7$ & $-4,6$ & $-4,3$ & $-1,2$ & 0 & 4 & 2,4 & 2 \\
\hline Formación bruta de capital fijo ……....................... & $-0,4$ & 3,6 & 5,7 & 7,9 & 14,1 & 4 & 1,3 & $-14,3$ & $-27,7$ & $-22,7$ & $-12,2$ & 8,6 & $-6,6$ & 14,3 & 26 & 12 \\
\hline Exportaciones & 6,7 & 4 & 0,8 & 7 & 5,2 & 5,7 & 6,8 & $-0,8$ & $-3,8$ & 6,2 & 5,1 & 2,1 & 2,5 & 12,1 & 13,4 & 6,9 \\
\hline Importaciones & 6,1 & 1,8 & $-1,4$ & 7,6 & 8,2 & 6,3 & 4,1 & $-2,9$ & $-9,7$ & 3,6 & $-0,3$ & 2,9 & 0 & 14,7 & 16 & 7,7 \\
\hline Contribuc. demanda doméstica al crecimiento..... & 3,5 & 3,6 & 2,7 & 3,7 & 7,4 & 5,4 & 3,3 & $-4,6$ & $-10,3$ & $-3,7$ & -3 & 0,6 & -1 & 4,6 & 7,7 & 4,1 \\
\hline Contribuc. demanda externa al crecimiento.......... & 1,6 & 2,5 & 1,8 & 0,8 & $-1,2$ & 0,3 & 2,6 & 1,5 & 4,1 & 2,9 & 5,4 & $-0,2$ & 2,7 & 0,1 & 0,1 & 0,4 \\
\hline 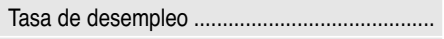 & 3,8 & 4,5 & 4,7 & 4,5 & 4,4 & 4,5 & 4,6 & 6,3 & 11,9 & 13,7 & 14,4 & 14,7 & 13,1 & 11,3 & 9,4 & 8,5 \\
\hline 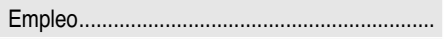 & 3 & 1,8 & 2 & 3,1 & 4,7 & 4,3 & 3,6 & $-1,1$ & $-8,1$ & $-4,2$ & $-2,1$ & $-0,6$ & 2,4 & 1,7 & 1,4 & 1,6 \\
\hline 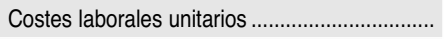 & 6,4 & 0,8 & 3,1 & 4,1 & 4,7 & 3,2 & 3,6 & 5,9 & $-3,7$ & $-6,5$ & $-3,2$ & $-0,8$ & 0,2 & $-1,6$ & $-1,2$ & $-0,8$ \\
\hline IPCA …… & 4 & 4,7 & 4 & 2,3 & 2,3 & 3,4 & 1,4 & 3,1 & $-1,7$ & $-1,6$ & 1,2 & 1,9 & 0,5 & 0,3 & 0 & 0,6 \\
\hline 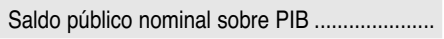 & 1,5 & $-0,4$ & 0,2 & 1,5 & 1,7 & 3 & 0,2 & $-7,3$ & $-13,9$ & $-30,9$ & $-13,4$ & -8 & $-5,7$ & $-3,9$ & $-2,3$ & $-1,1$ \\
\hline 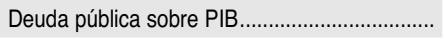 & 36,4 & 32,1 & 31,1 & 29,4 & 27,5 & 24,9 & 25 & 44,3 & 64,9 & 92,2 & 106,4 & 120,2 & 120 & 107,5 & 93,8 & 89,1 \\
\hline Saldo balanza cuenta corriente sobre PIB ....... & $-0,3$ & -1 & 0 & $-0,8$ & $-3,1$ & $-3,5$ & $-5,4$ & $-5,6$ & $-2,3$ & 1,1 & 1,1 & $-1,5$ & 3,1 & 3,6 & 3,6 & 3,7 \\
\hline Saldo balanza comercial sobre PIB .................. & 29,9 & 25,1 & 21,8 & 19,8 & 17,4 & 14,1 & 11,8 & 13,2 & 20,1 & 22,8 & 23 & 21,5 & 19,5 & 22,4 & 28,1 & 28,4 \\
\hline Tasa de prétamos sobre depósitos ..................... & 113,5 & 135,2 & 138,0 & 157,4 & 162,0 & 161,7 & 175,9 & 190,5 & 173,4 & 170,6 & 161,9 & 151,6 & 142,2 & 124,5 & 116,1 & nd \\
\hline Endeudamiento hogares sobre renta disponible.. & 110,7 & 126,2 & 147,2 & 170 & 201 & 225,8 & 236,2 & 231,9 & 240,8 & 237,4 & 236,4 & 229,1 & 224,5 & 207,3 & nd & nd \\
\hline Tasa préstamos morosos sobre prést. brutos.. & 1 & 1 & 0,9 & 0,9 & 0,5 & 0,5 & 0,6 & 1,9 & 9,8 & 13 & 16,1 & 25 & 25,7 & 20,7 & 18,8 & nd \\
\hline
\end{tabular}

